\title{
As variáveis ambientais, as estradas regionais e o fluxo das tropas em Diamantina, MG: 1870-1930
}

Marcos Lobato Martins Faculdade Pedro Leopoldo (MG)

\section{RESUMO}

Este trabalho mapeia as estradas no entorno de Diamantina e analisa as condições de funcionamento das tropas de muares, responsáveis pelo transporte de pessoas e mercadorias no Alto Jequitinhonha na virada do século XIX para o século XX. As variáveis ambientais regionais (topografia, tipos de solos, pluviosidade, temperaturas, características dos rios etc.) são apontadas como fatores decisivos, de um lado, para explicar a permanente precariedade das estradas e, de outro lado, para desestimular os investimentos locais em estradas de rodagem e empresas de transporte rodoviário. Dessa forma, o "antigo sistema de circulação" ganhou sobrevida na região até bem adiantado o século XX.

Palavras-chave: Ambiente; Estradas; Permanência das tropas de muares.

\section{ABSTRACT}

This article maps the roads around Diamantina (Minas Gerais) and analyses the working conditions of mule trains, responsible for the transportation of people and goods in the Upper Jequitinhonha region on the turn of the $19^{\text {th }}$ to the $20^{\text {th }}$ Century. Regional environmental variables, like topography, types of soil, temperature, rainfall, river characteristics and useful natural resources etc., are seen as decisive factors, on one hand, to explain the road's permanent precariousness and, on the other hand, to discourage local investments in roadways and carrier services. Thus, the ancient circulation system survived in the region well up to the mid- $20^{\text {th }}$ century.

Keywords: Environment; Roads; Continuity of mule trains.

A percepção de que as atividades agropecuárias guardam relação com as condições ambientais é amplamente difundida. As características do solo, as temperaturas, a disponibilidade de chuva e de água, são fatores que influem sobre a produção das lavouras. Menos conhecida é a dependência do garimpo de ouro e de diamante perante o ritmo das estações do ano. As atividades mineradoras, manuais e semimecanizadas, praticadas no interior de Minas 
Gerais, Bahia, Goiás e Mato Grosso, dependem das chuvas, ou melhor, da ausência de chuvas. Os serviços de lavra são tocados no período da seca, entre março e setembro. Desse modo, há que reconhecer que a história da região de Diamantina é, significativamente, condicionada pelo meio ambiente.

O que ainda pouco se discute é o modo como as variáveis ambientais interferiram — a ponto de moldar e incitar continuidades — sobre o fluxo das mercadorias e dos viajantes na região do Alto Jequitinhonha. Em que medida o "antigo sistema de circulação", baseado nas tropas burriqueiras, a construção e a manutenção das estradas requerem, para sua compreensão histórica, a consideração de fatores como o relevo, o clima, a hidrografia? O objetivo deste trabalho é precisamente iniciar essa discussão.

\section{O AMBIENTE NO AlTo JEQUiTINHONHA}

Em manual escolar de geografia publicado no ano de 1899, o professor José Augusto Neves elaborou um "resumo corográfico" do município de Diamantina. Naquele ano, as terras que compunham o município eram muito vastas, de modo que boa parte do Alto Jequitinhonha pertencia à jurisdição política do velho arraial do Tijuco. ${ }^{1} \mathrm{O}$ município limitava-se, ao norte, com Bocaiúva; a nordeste, com Montes Claros; a leste, com o Serro e, a sudeste, com o município de Conceição do Serro (atual Conceição do Mato Dentro). A superfície de Diamantina, na virada do século XIX para o XX, alcançava $7.800 \mathrm{~km}^{2}$, compreendendo diversas paisagens.

Neves afirma que Diamantina tem "seu esqueleto orográfico formado pela cordilheira do Espinhaço” (op. cit., p.126), que é o divisor de águas das bacias dos rios Doce, Jequitinhonha e São Francisco. Por isso, a maior parte da superfície do município é formada por "um extenso planalto irregular, essencialmente elevado". Nessa parte das terras diamantinenses, ricas em ouro e diamantes, "nascem muitos rios, ribeirões e riachos com elevadas quedas d'água". José Augusto Neves dividia o município de Diamantina em três regiões bem demarcadas, com aspectos físicos distintos. A primeira delas seria a região sertaneja, domínio do cerrado, com clima quente e chuvas regulares, distribuídas de outubro a abril. Essa região compreenderia os vales do baixo Paraúna, dos rios Pardo Grande e Pequeno, Curimataí, Manso, Preto e Araçuaí. Na região sertaneja localizavam-se os distritos de Curimataí (atual Buenópolis), Nossa Senhora da Glória, Rio Manso (atual Couto Magalhães de 
Minas), Rio Preto (atual São Gonçalo do Rio Preto) e Mercês de Araçuaí (atual Senador Modestino Gonçalves).

A segunda região seria a alpina ou diamantina, espaço das terras altas e movimentadas, cobertas pelos campos rupestres, serras de grés e numerosas fontes permanentes de água cristalina. A região alpina compreenderia os vastos planaltos diamantinos e os vales superiores dos rios Jequitinhonha, Doce, Velhas e Jequitaí. No interior dessa região situavam-se os principais distritos de paz do município: Santo Antônio de Diamantina (sede), Curralinho (atual Extração), São João da Chapada, Datas, Gouveia, Inhaí, Pouso Alto (atual Presidente Kubitschek) e Campinas de São Sebastião (atual Senador Mourão).

A terceira região que comporia o município de Diamantina, conforme José Augusto Neves, era a carrasquenta ou dos chapadões, hoje domínio das florestas de eucalipto e de lavouras de café, compreendendo terrenos em níveis altos, com boa aguada para cultura. Nessa região situam-se localidades como Pé do Morro (antigo registro na época da Demarcação Diamantina) e Galinheiro (atual Planalto de Minas).

Quanto ao clima, que o autor referido considerava saudável, destacavase a ocorrência de temperaturas mais altas nos vales dos rios e na região sertaneja. As temperaturas eram mais amenas no planalto carrasquento, ao passo que, na região diamantina, o clima era mais temperado, com invernos bastante rigorosos. Nas terras acima de mil metros, como as localidades de São João da Chapada, Diamantina e Datas, as temperaturas entre maio e agosto chegavam a cair próximo de zero, durante as madrugadas. Também nas terras altas e nas encostas das serras que cortavam o município de Diamantina as chuvas eram abundantes, ao redor de 2.500 milímetros anuais, concentradas entre os meses de setembro e abril. O solo dos altos planaltos diamantinos era, conforme Neves, "composto de terras saibrosas, cretáceas e argilosas, de envolta com fragmentos de mica e quartzo" (op. cit., p.128). Dessa forma, os domínios dos campos rupestres configuram áreas ruins para a lavoura e as pastagens, mas ricas em mananciais de água potável, lavras de ouro e diamante.

No município de Diamantina, destacavam-se as serras do Cabral (no distrito de Curimataí), do Arrenegado e da Inhacica (no distrito de Inhaí), da Paciência (no povoado de Pinheiro), do Dumbá (no distrito de Datas), do Gavião (que separava os distritos de Rio Preto e Curralinho do Rio Vermelho do município do Serro), dos Azevedos, das Andorinhas, do Riacho dos Ventos e do Cemitério do Peixe (no distrito de Gouveia), da Pantinha (no distrito de Pouso Alto) e a Serra Menina (no distrito de Araçuaí). Portanto, para alcançar a cidade de Diamantina — a mais populosa da região e principal 
centro comercial e educacional do Norte de Minas - era preciso vencer elevações que superavam, freqüentemente, mil e duzentos ou mil e trezentos metros de altitude. Os viajantes deviam vencer terrenos íngremes, de relevo muito movimentado, pontuado por numerosíssimos afloramentos rochosos, numa marcha por trilhas sinuosas e difíceis.

Nos vales dos rios e nas encostas das serras, José Augusto Neves assinalou a presença de muitas florestas, onde havia grande quantidade de excelentes madeiras de lei: jacarandás, angicos, cedros, perobas, aroeiras, sucupiras, braúnas etc. Nas matas e capoeiras do município viviam veados, quatis, capivaras, pacas, queixadas, antas, tatus, tamanduás, preguiças e as temíveis onças (a pintada ou canguçu e a preta ou tigre). Nos afloramentos de rochas, nos campos e nas matas rastejavam diversas espécies de cobras: a preta, papa-pinto, cascavel, jararaca, coral, verde, cipó, sucuriú, a cobra de vidro, a de duas cabeças etc.

Os cursos d'água que banhavam o município eram numerosos. José Neves indicou dezenas deles, descrevendo suas nascentes, percursos e desemboques. Nas proximidades de Diamantina, o viajante depararia com vários rios e ribeirões, afluentes do Jequitinhonha. Ao sul da cidade: Três Barras, Capivari, Lomba, Ribeirão do Inferno, Santa Maria e Ajunta-Ajunta. Ao norte de Diamantina: Pinheiro, Caetemirim, Inhacica Grande, Inhacica Pequeno, Contendas, Macaco Grande, Ribeirão Pindaíbas, Rio Manso. Segundo José Augusto Neves, havia uma extensa ponte de madeira sobre o Jequitinhonha no arraial de Mendanha, três pontes sobre o rio Araçuaí, uma sobre o rio Pardo Grande no distrito de São João da Chapada (construída em madeira a expensas de particulares), duas sobre o rio Preto (uma pública, na entrada do arraial, e outra feita por particulares, 9 quilômetros rio acima) e uma ponte sobre o AjuntaAjunta, a 7 quilômetros de Diamantina (op. cit., p.128-35). Tantos rios e tão poucas pontes significavam que, na virada do século XIX para o século XX, os viajantes eram obrigados a atravessar os cursos d'água improvisando pinguelas ou diretamente em vaus conhecidos pelos habitantes da região.

\section{O ANTIGO SISTEMA DE CIRCUlaÇÃo NO Alto JEQUitinHONHA}

No vasto interior do Brasil, por quase quatro séculos predominou o "antigo sistema de circulação", baseado na combinação de caravanas de muares, carros de boi e, nos cursos fluviais navegáveis, canoas. As tropas representaram a face mais visível da circulação antiga, principalmente no Sul, em São 
Paulo e Minas Gerais. A cena típica do Brasil escravista, no que se refere ao transporte de pessoas e mercadorias, era o lote de burros conduzido pelo tropeiro montado no cavalo madrinheiro da tropa.

O exame detalhado revela que o "antigo sistema de circulação" possuía diversos elementos interconectados, que davam concretude histórica a práticas culturais solidamente enraizadas na sociedade brasileira. Um primeiro elemento é a rede intricada e mutável de caminhos e estradas que cortava as regiões do país. Caminhos rústicos, percorridos com lentidão a pé ou em montarias, cheios de perigos e sinuosidades. Sobre eles, Capistrano de Abreu escreveu que "um caminho destes oscila naturalmente antes de fixar-se, e assim não é fácil apurar qual foi seu primeiro rumo" (p.273). ${ }^{2}$ Abertos a partir do litoral, os caminhos antigos devassaram o interior, muitas vezes convergindo para as regiões que abrigavam vilas e arraiais de maior dimensão, centros importantes de mineração e comércio.

Um segundo elemento do "antigo sistema de circulação" é a tropa de muares propriamente dita, dezenas de animais cargueiros conduzidos por poucos homens, genericamente chamados tropeiros. No cotidiano das tropas, elementos simbólicos e materiais distinguiam o labor dos tropeiros, cujo fluxo pelos caminhos antigos era viabilizado pelo concurso dos afazeres de ofícios conexos. Nas margens das estradas, a existência de colonos, fazendas, vendas e ranchos garantia a trafegabilidade contínua, o ir e vir dos viajantes e dos tropeiros.

Um terceiro elemento do "antigo sistema de circulação", elaborado paulatinamente e que adquire relevância com a intensidade crescente do trânsito em muitos caminhos, é a legislação sobre as estradas. Baixada pelos governos das Capitanias/Províncias, a execução dessa legislação ficava a cargo das Câmaras de Vereadores. Os regulamentos sobre a "polícia das estradas" determinavam as obrigações das autoridades, dos moradores e dos viajantes referentes ao uso, à abertura e à manutenção dos caminhos.

Os viajantes estrangeiros que percorreram Minas Gerais no século XIX deixaram muitos registros sobre as tropas, os tropeiros e as dificuldades das viagens. Na região do Nordeste mineiro, onde as tropas resistiram até a década de 1960, eram chamados bruaqueiros os homens que levavam dois ou três animais cargueiros, em percursos curtos. A tropa regional típica era composta por lote de dez cargueiros, mais um cavalo (ou égua) madrinheiro. ${ }^{3} \mathrm{Na}$ frente da caravana seguia o burro de guia, munido de peitoral com seis cincerros e "pisteira" de pura prata, adornando a parte frontal da cabeça. Esse animal, que carregava menos peso que os demais, possuía a função de marcar a via- 
gem. Bem treinado, ele sabia os caminhos que a tropa percorria e impedia que os outros cargueiros passassem à sua frente nas encruzilhadas e nas paradas. O madrinheiro, montado pelo dono da tropa, andava bem adornado e solto no meio da tropa. O burro de coice, geralmente o mais carregado de todos os animais da tropa, seguia no fim da fila. Sua tarefa era a de empurrar os animais do meio que parassem de marchar. Fechando a caravana, aparecia uma pequena mula carregada com os apetrechos da cozinha e os mantimentos dos tropeiros.

Nas pequenas tropas do Alto Jequitinhonha, a divisão de trabalho era relativamente simples. O dono da tropa — ou um seu auxiliar de confiança, chamado de arrieiro - cuidava da compra e venda de mercadorias, entabulando negociações com comerciantes e moradores do local de destino da caravana. Dessa forma, para indicar prestígio, o dono da tropa andava todo arrumado. Ao aproximar-se do mercado ou rancho, tomava banho em um córrego e mudava de roupa. ${ }^{4}$ Os tocadores, geralmente dois, no máximo três homens, cuidavam dos animais, arriavam, carregavam e descarregavam os cargueiros. Eram os responsáveis pela maioria das tarefas do transporte, que enchiam o tempo no decorrer dos caminhos e nas paradas, nos ranchos e mercados. O cozinheiro da tropa, geralmente uma criança, preparava o café e as refeições nos pousos, além de ajudar os tocadores a carregar e descarregar os animais.

Na região do entorno de Diamantina, caracterizada pelo relevo bastante movimentado, a marcha diária dos cargueiros era de cerca de três léguas e meia $(21 \mathrm{~km})$; no máximo, quatro léguas $(24 \mathrm{~km})$. Essa distância, uma vez percorrida nas primeiras horas da manhã, ensejava o pouso da tropa num rancho. ${ }^{5}$ No pouso, os tocadores descarregavam os animais, desarriavam-nos e raspavam seus pêlos, davam-lhes tratos ou pasto. As cargas eram arrumadas cuidadosamente num canto do rancho e cobertas com couros. A comida era preparada. No dia seguinte, a tropa retomava a viagem.

As pequenas tropas do Nordeste mineiro carregavam poucos tipos de apetrechos, a maioria feita em couro. A cozinha da caravana era composta de trempe (tripé desmontável com ganchos nas hastes) e panelas de ferro. As cangalhas dos cargueiros eram de madeira, recebendo bruacas de couro ou os balaios de custa, fabricados com madeira trançada. Nas bruacas e nos balaios eram acondicionadas as cargas, cobertas com couro de boi. Cada burro da tropa recebia uma cangalha, o "dobro" (pano colocado como forro entre o costado do animal e a cangalha ou arreio), o peitoral (colar de couro que prendia a cangalha), a "retranca" (rabicho colocado atrás do animal, para impedir a cangalha de escorregar) e a "sopradeira" (uma espécie de bocal que impedia 
o animal de comer na estrada), as duas últimas peças também feitas com couro de sola. ${ }^{6}$

A carga dos animais acostumados ao trabalho da tropa girava em torno de oito arrobas $(120 \mathrm{~kg})$, mas os mais fortes podiam levar até dez arrobas (150 $\mathrm{kg}$ ). Durante a marcha, era comum acontecer de burros ou mulas jogarem fora a carga ou de animais caírem paralisados, porque não suportavam o peso. Era preciso, nesses casos, que os tocadores descarregassem os animais, levantassem-nos e colocassem novamente a carga sobre eles; só então a viagem poderia ser retomada. Na realidade, o maior cuidado que o tropeiro devia ter era justamente com a acomodação das cargas sobre os animais. A cangalha, os arreios e as bruacas não podiam machucar o cargueiro, porque, do contrário, ele pararia e deitaria no meio do caminho. Conforme diziam os tropeiros, a cangalha não podia "pisar no animal", provocando uma ferida no seu dorso. O dono da tropa deveria "olhar, bater, fofar a falha de maneira que a cangalha não tocasse no lugar que estava machucando". ${ }^{7}$ Outro cuidado fundamental com os animais, para conservá-los sempre gordos e fortes, era o de fornecer-lhes alimentação apropriada: muito milho, fubá e cana, não bastando o capim dos pastos.

Convém frisar que, associada ao tropeirismo gaúcho, formou-se uma imagem idealizada do tropeiro, que enfatiza traços como o aventureirismo e uma indumentária rica e característica, com predomínio de peças de couro. Assim, o tropeiro gaúcho é descrito portando chapelão de feltro de abas viradas, camisa de pano forte, manta ou beata com uma abertura no centro, jogada sobre o ombro, botas de couro flexível que chegavam até o meio da coxa. Não era assim que se apresentava o tropeiro da região de Diamantina na virada do século XIX para o XX. No ano de 1899, em visita à cidade, H. D. Beaumont, Segundo Secretário da Legação Britânica no Rio de Janeiro, escreveu sobre os tropeiros:

Os condutores são sempre negros ou mulatos em trajes leves, que caminham descalços e trazem muitas vezes bizarros chapéus de couro da Bahia ... nunca exigem cama. Eles dormem em uma guarda com a sela de seus animais como travesseiros. (O Município, ano IV, n.230, 16.06.1900, maço 43. Biblioteca Antônio Torres)

O diplomata inglês afirmou que, "segundo o hábito do Brasil", os tropeiros não tinham coberta alguma e viajavam descalços. Estas observações são corroboradas pelo depoimento de Joaquim dos Santos Júnior — para quem 
a "tropeirada andava toda suja, de tanto ficar carregando peso", trajando roupas velhas e gastas - bem como pelo depoimento de Augusto Domingos Ribeiro - que indica que os tocadores utilizavam o "dobro" dos animais como cobertor e os couros que guarneciam as cargas como esteira para dormir.

Portanto, os tocadores das tropas do Nordeste de Minas Gerais possuíam vestimenta bem distinta daquela de seus congêneres gaúchos, sem botas de couro e mantas grossas. Para aquecer nas noites frias, contavam apenas com o fogo aceso nos ranchos.

A alimentação dos homens das tropas da região de Diamantina era constituída por toucinho, carne de sol, feijão, farinha e café. Durante as viagens, os tropeiros raramente consumiam cachaça, que era usada, quando os dias estavam muito frios, como remédio para prevenir constipação; a cachaça também era empregada como alívio para a picada de insetos.

As tarefas penosas, pesadas e rotineiras dos tocadores, suas vestimentas pobres e o pouquíssimo dinheiro de que dispunham afastam o tropeiro do Alto Jequitinhonha do modelo idealizado do tropeiro do Centro-Sul do Brasil.

Atividades complementares deram suporte ao vai-e-vem dos tropeiros. O "antigo sistema de circulação" fez surgir ocupações como a de rancheiro, ferrador, peão ou amansador e acertador. $O$ ferrador pregava as ferraduras nos animais da tropa e também atuava fazendo as vezes de veterinário. O peão era o amansador de eqüinos e muares à moda do sertão, necessário para transformar os animais "chucros" em potenciais cargueiros das tropas. O trabalho do peão era finalizado pelo acertador, homem hábil e paciente, que ensinava andaduras ao animal e educava-lhe a boca ao contato do freio. ${ }^{8}$

Porém, a mais destacada das atividades conexas ao tropeirismo era a do rancheiro, isto é, do proprietário de rancho. O rancho era um abrigo que recebia os tropeiros e as cargas, consistindo de um galpão aberto ou com paredes de meia altura. Ao redor do rancho havia esteios para amarrar os animais. Ao lado do rancho, um pequeno cômodo de comércio, explorado pelo rancheiro e sua família. Os tropeiros pagavam o milho e o pasto consumido pelos animais, conforme uma taxa cobrada sobre o número de cangalhas. ${ }^{9} \mathrm{~A}$ propósito dos ranchos existentes nos caminhos que levavam a Diamantina, H. D. Beaumont escreveu:

O tratamento ... não é luxuoso, porém, em muitos destes ranchos o asseio é perfeito. Durante nossa viagem, com quinze animais e três camaradas, o dispêndio de rancho montou entre 40 e 50 mil réis. Eis a conta que foi paga em um rancho da comprida estrada em uma noite ... : 
40 litros de milho . . . . . . . . $6 \$ 800$

1 garrafa de cachaça . . . . . . . . 1\$500

1 garrafa de cerveja . . . . . . . 3 $\$ \$ 000$

Jantar para 4 pessoas . . . . . . . 10\$000

Almoço para 5 pessoas . . . . . . . 3 $\$ \$ 000$

3 camas . . . . . . . . . . . 3\$000

Pasto para os animais . . . . . . . 1 $1 \$ 590$

Total . . . . . . . . . . . . 28 $\$ 000$

(O Município, ano IV, n.230, 16.06.1900. Biblioteca Antônio Torres)

Ao prestar serviços para os viajantes e fornecer abrigo para os tropeiros e pasto para os animais, os ranchos eram parte da "infra-estrutura" necessária para o funcionamento do "antigo sistema de circulação". Como observara Capistrano de Abreu, os ranchos surgiram espontaneamente no entorno dos caminhos mais movimentados, pois:

a experiência ensinou certos povoadores a estabelecerem-se pelos caminhos, a fazerem açudes, a plantarem mantimentos, que não precisavam ser exportados, porque se vendiam na porta aos transeuntes, a comprarem as reses transviadas ou desfalecidas que, tratadas com cuidados, ou serviam à alimentação ou revendiam com lucro. (op. cit., p.285)

Os caminhos mais movimentados e seguros eram justamente aqueles cercados por fazendas e sítios, nos quais os viajantes poderiam encontrar hospedagem, algum comércio e lavouras. Víveres a baixo preço, serviços e apoio para as caravanas.

Em Diamantina, cidade para a qual convergiam tropas de todo o Norte de Minas Gerais, havia muitos negócios diretamente associados ao movimento dos viajantes e das cargas. Conforme Ciro Arno (op. cit., p.13), na década de 1880 a cidade possuía três grandes ranchos de tropas, que eram chamados pelo povo de "intendências". Havia a intendência do Laje ou intendência de baixo, de propriedade de Joaquim Casimiro Laje. Manoel César Pereira da Silva era proprietário de outra intendência, a "do meio", situada no mesmo largo e em frente à do Laje. Juca Corrêa era dono da terceira intendência, a "de cima”, localizada atrás da Igreja da Sé, contígua ao velho cemitério. Outro co- 
merciante envolvido com a prestação de serviços aos tropeiros e viajantes era Salustiano Amâncio da Rocha. Em janeiro de 1887, um jornal diamantinense publicou anúncio de seu estabelecimento:

Pechincha. Na loja de Salustiano Amâncio da Rocha vendem-se fazendas, e muitos outros objetos chegados recentemente, com grande redução de preços. É para acabar, aproveitem. Ruas da Quitanda e do Comércio, antiga Loja de Paris. (Sete de Setembro, ano I, n.17, 01.01.1887, p.4. Biblioteca Antônio Torres)

Dez anos depois, o jornal O Município anunciava que Salustiano Rocha havia se mudado para Sete Lagoas, levando para lá os negócios que tivera em Diamantina: armazém, rancho e hotel (O Município, ano III, n.89, 31.10.1896. Biblioteca Antônio Torres). Nos anos de 1887 e 1888, o Sete de Setembro publicou anúncios de Antônio Casimiro de Almeida, que possuía negócio de animais para alugar: "Antônio Casimiro de Almeida tem bons animais de sela para alugar a $15 \$ 000$ por dia. Rua do Bonfim, em frente a do Amparo" (Sete de Setembro, ano I, n.17, 01.01.1887, p.4. Biblioteca Antônio Torres). O mesmo periódico publicou, entre 1886 e 1888, anúncios de João Raymundo, proprietário de hotel na cidade de Diamantina. Em meados da década de 1890, foi a vez de o "Grande Empório do Norte", da poderosa firma comercial Motta \& Cia., anunciar sua entrada no ramo da hospedagem de viajantes e tropeiros, publicando reclame no jornal O Município:

Hotel e Restaurante Familiares, Rua da Quitanda, prédio contíguo à casa comercial dos srs. Motta \& Cia. Diamantina. Este novo estabelecimento acha-se bem montado, dispondo de aposentos asseados e arejados ... prontidão de serviços, ordem e moralidade ... Preços módicos. Dinheiro à vista. Gerente: José Altimiras Rocha. (O Município, ano I, n.38, 27.07.1895. Biblioteca Antônio Torres)

Na década de 1910, as atividades de prestação de serviços para tropeiros e viajantes continuavam vigorosas na cidade de Diamantina. Por ordem do Procurador Geral do Município, Arthur da Fonseca Ribeiro, a Coletoria Municipal de Diamantina fez publicar, em novembro de 1912, a lista dos contribuintes do imposto de indústrias e profissões para o exercício de 1913 (distrito sede). Nessa lista constam os nomes de pessoas que exploravam serviços conexos ao transporte de tropas, conforme o Quadro 1. 


\section{Quadro 1}

Serviços conexos ao transporte

de tropas - Distrito de Diamantina - 1912

\begin{tabular}{ll}
\hline Nome & Ramo \\
\hline Antônio Casimiro de Almeida & Pasto de aluguel \\
\hline Gabriel Amarante & Pasto de aluguel \\
\hline D. Maria Tereza Jamar & Pasto de aluguel \\
\hline Miguel Antônio Coelho & Cocheira \\
\hline Ramiro Fernandes de Azevedo & Cocheira \\
\hline Octávio Ferreira Horta & Hotel \\
\hline Trajano Gomes Ribeiro & Hotel \\
\hline Francelino Horta \& Cia. & Hotel \\
\hline
\end{tabular}

Fonte: A Estrela Polar, ano X, n.46, 24.11.1912. Biblioteca Antônio Torres.

Os dados apresentados anteriormente são suficientes para mostrar que havia, na cidade de Diamantina, uma "infra-estrutura" capaz de receber os viajantes e os tropeiros que nela faziam negócios, na virada do século XIX para o XX.

\section{A AUTORIDADE GOVERNAMENTAL E O CONTROLE DAS ESTRADAS}

Imprescindíveis para o povoamento do território e para o desenvolvimento das economias locais e regionais, os caminhos e as estradas logo despertaram as atenções das autoridades do governo.

Nos tempos coloniais, muitos caminhos foram abertos por demanda dos vice-reis e governadores, como é o caso do Caminho Novo para as Minas Gerais. Dos moradores vizinhos a esses caminhos exigiam-se recursos e trabalho para a manutenção e a construção de pontes, fossos, valetas de escoamento das águas. Patrulhas de tropas regulares freqüentemente vigiavam as estradas principais, nas quais também foram instalados os registros fiscais. ${ }^{10}$

A Lei $n^{\circ} 310$, de 8 de abril de 1846, decretada pela Assembléia Legislativa Provincial de Minas Gerais e sancionada pelo presidente da Província, Dr. Quintiliano José da Silva, classificou as estradas mineiras em provinciais e 
municipais e estabeleceu providências relativas à sua abertura e conservação (Livro da Lei Mineira, 1846, Tomo XII, Parte 1ª, Fl. 13. Arquivo Público Mineiro). O artigo primeiro da referida lei fixava a cobrança de taxas itinerárias nas estradas provinciais, aquelas construídas e mantidas pela Província. O artigo terceiro criou o cargo de Inspetor de Estradas nos municípios da Província, nomeado de dois em dois anos pelo governo a partir de proposta da Câmara Municipal, para atuar em "círculos" que seriam determinados pela autoridade provincial. Esses inspetores teriam, entre outras, as seguintes funções: dirigir os trabalhos de construção de estradas e fiscalizar sua conservação; implantar sinalização por placas nas encruzilhadas das estradas. Conforme a Lei $n^{\circ} 310$, o conserto das estradas municipais dependia de autorização expressa do presidente da Província, precedida por informações da Câmara Municipal e do inspetor do círculo. Quanto ao trabalho requerido para as obras de manutenção das estradas, a Lei n 310 determinava que todos os chefes de família, proprietários e trabalhadores, poderiam ser chamados a doar, a cada ano, dois dias de trabalho: 1) por indivíduo de saúde regular, com idade entre 18 e 60 anos; 2) ou por carro de bois ou por cavalos e bestas empregados nos estabelecimentos. Essa prestação poderia se fazer em dinheiro ou em serviço (artigos 12 a 14).

Dessa forma, pode-se concluir que a legislação provincial sobre as estradas fazia recair sobre os ombros dos moradores e das Câmaras Municipais o ônus de garantir a trafegabilidade contínua dos caminhos.

Anos depois, o Regulamento de Polícia das Estradas da Província, estabelecido pela Diretoria Geral das Obras Públicas em $1^{\circ}$ de julho de 1884, fixou proibições para moradores marginais e usuários das estradas, com as respectivas multas por infração das determinações. ${ }^{11}$ As proibições eram numerosas: acampar e fazer fogo na vizinhança das pontes, escavar o leito das estradas ou nele fincar estacas, depositar pedras, madeiras, entulhos etc. nos caminhos, entupir as valetas e os bueiros de esgoto, abrir regos d'água a menos de doze metros das estradas ou fazer represas, açudes etc. na sua parte superior, impedindo de qualquer modo o livre escoamento das águas. No que se refere à polícia de trânsito, o Regulamento estabelecia dimensões para os carros e carroças (largura entre as rodas, das pinas das rodas, tipos dos pregos fixadores das pinas), que deveriam ser todos de eixos fixos. As Câmaras Municipais ficaram incumbidas de fiscalizar o cumprimento das disposições sobre trânsito de carros e de promover sua matrícula e licenciamento. As Câmaras cobrariam as multas sobre carros e carroças, aplicando os recursos obtidos no melhoramento dos caminhos vicinais. 
Para a região de Diamantina, que muito lentamente desligou-se das estruturas do passado, os depoimentos de ex-tropeiros que trabalharam, desde as décadas de 1930 e 1940, com caravanas de cargueiros evidenciam a precariedade da fiscalização nas estradas. No Alto Jequitinhonha, a "polícia dos caminhos" era algo virtual, na virada do século XIX para o XX. Os antigos registros da época colonial estavam inteiramente desativados. Nem mesmo o posto de pedágio e de fiscalização que havia sido instalado na ponte de Mendanha, quando de sua inauguração no início da década de 1860, permanecia em operação no ano da viagem de H. D. Beaumont àquele distrito, em 1899. Augusto Domingos Ribeiro, que conduziu tropas entre o Serro e Diamantina nos idos de 1940, nunca encontrou fiscalização nos caminhos ou nos ranchos da região. Conforme suas palavras, a fiscalização das tropas ocorria somente nos mercados das duas cidades:

Neles, havia balança que o fiscal usava para pesar as mercadorias. O fiscal conferia as entregas e até olhava para as tropas. Se a tropa chegasse com um animal 'pisado' ou doente, o fiscal falava não! Esse animal não podia trabalhar mais, porque o fiscal não deixava.

Na mesma direção vai o depoimento de José Maria Lopes, como também o de Joaquim dos Santos Júnior. Para este último, "os fiscais do Mercado [de Diamantina] olhavam o comércio da cidade e até de alguns povoados, e fiscalizavam as tropas estacionadas nas ruas próximas da Intendência para ver se carregavam alguma muamba”. Mais enfática é a fala de Nestor Araújo, ex-cozinheiro de tropa: "nas estradas não tinha nenhuma fiscalização, ninguém tomava conta das estradas e, nos ranchos, só havia o olho do dono". O governo mineiro e as municipalidades não possuíam meios nem dinheiro para tornar realidade as prescrições contidas no Regulamento de Polícia das Estradas, exceto nas imediações ou no interior das sedes municipais.

A legislação mencionada anteriormente permaneceu inalterada até a década de 1910. Assim, em plena República, a construção e a conservação das estradas de rodagem ainda não constituíam serviço separado e sistematizado no âmbito do governo mineiro. Com poucos recursos orçamentários e absorvidas pelas promessas de progresso e modernização trazidas pelas ferrovias, que avançavam no Sul e na Mata, as autoridades mineiras seguiram indiferentes às agruras vividas pelos moradores servidos apenas pelos caminhos trilhados pelas tropas de muares. Talvez porque acreditassem que os animais 
cargueiros operassem do mesmo modo em qualquer terreno ou caminho. Afinal, a mula é lenta, mas chega ao destino...

\section{CAMINHOS E ESTRADAS NA REGIÃo DE DiAmANTINA}

No decurso da história, os modos de traçar, construir e conservar estradas sofreram transformações expressivas, fornecendo provas da engenhosidade humana.

As estradas primitivas limitavam-se à limpeza de alguns trechos, desvio de banhados e, quanto ao mais, seguiam todas as sinuosidades do terreno, procurando sempre os vales e as gargantas. Eram caminhos simplesmente indicados na paisagem, pela freqüência do trânsito de pessoas e animais. Não havia consolidação da chapa destinada ao tráfego, nem valetas laterais para desviarem as águas da chuva.

Nas áreas de relevo movimentado, os caminhos primitivos eram bastante difíceis. Descrevendo uma viagem entre São Vicente e São Paulo, realizada em 1585, Fernão Cardim escreveu:

O caminho é tão íngreme que às vezes íamos pegando com as mãos ... Todo o caminho é cheio de tijucos, o pior que nunca vi, e sempre íamos subindo e descendo serras altíssimas e passando rios caudais de água frigidíssima. (Apud Abreu, op. cit., p.263)

No século XVIII, os caminhos que chegavam ao arraial do Tijuco correspondiam a essa descrição. Eram picadas sinuosas, repletas de rampas acentuadas, atravessando matas espessas nos vales dos rios e nas encostas, brejos nos terrenos planos ocupados pelos campos rupestres; os viajantes esbarravam amiúde em grandes maciços de pedra, cujo contorno era demorado. Precisavam ainda evitar fossos profundos e encontrar passagens estreitas entre obstáculos do terreno acidentado.

Mesmo a chamada Estrada Real, que se estendia para o norte até a vila de Minas Novas, rota de escoamento do ouro e dos diamantes lavrados na região de Diamantina, não passava de uma rústica trilha de animais.

Partindo de Diamantina, havia três estradas principais. A primeira delas, rumando para o sul, atravessava o rio Jequitinhonha na altura de São Gonçalo do Rio das Pedras, e seguia na direção de Conceição do Serro e de Itambé do Mato Dentro. As autoridades provinciais chamavam-na de Estrada Geral do Norte. A segunda estrada alcançava Minas Novas e Araçuaí, cruzando o rio 
Jequitinhonha na localidade de Mendanha e o rio Araçuaí na localidade de Mercês de Araçuaí. A terceira estrada era conhecida pelo nome de Estrada do Gavião; ligava o Tijuco à área da Mata de Peçanha, porção leste do termo do Serro, onde ficavam situados os povoados de Peçanha e Rio Vermelho. Numerosas estradas vicinais convergiam para estes três caminhos principais, possibilitando o acesso a fazendas e povoados do Alto Jequitinhonha.

À medida que cresceram a população e a economia regional, no decorrer dos séculos XVIII e XIX, o incremento do fluxo de viajantes e de caravanas nas estradas principais do Alto Jequitinhonha exigiu maior atenção das autoridades e dos moradores para com a melhoria e a conservação dos caminhos. A manutenção dos caminhos vicinais e rurais recaiu, de fato, sobre os próprios moradores de suas margens. Estes limpavam as estradas todo ano, construíam desvios quando necessário, tapavam os buracos com tocos e pedras, materiais abundantes na região. ${ }^{12}$ A construção de pontes exigia a união de muitos interessados no trânsito pela localidade, que doavam madeira e trabalho para a edificação dessas obras-de-arte. Tarefa esta que necessitava ser repetida periodicamente, pois a madeira das pontes apodrecia e elas caíam parcial ou inteiramente.

Nos caminhos principais, a manutenção e a melhoria do trânsito exigia esforços mais avultados, bancados pelas Câmaras Municipais e pelo governo mineiro. Para conseguir condições de trafegabilidade permanente, era necessário realizar trabalhos de: a) escoamento fácil e rápido de águas pluviais, com a construção de valetas laterais; b) consolidação da chapa de rodagem, para que ela não amolecesse com a chuva; e; c) concordância do perfil longitudinal da estrada com as rampas, para o melhor aproveitamento do poder de tração dos animais. ${ }^{13}$ Outra necessidade era a construção e manutenção de pontes, para facilitar as passagens sobre os numerosos córregos e rios da região.

Duas iniciativas pioneiras para a melhoria das estradas da região de Diamantina ocorreram na primeira metade do século XIX. Na década inaugural do Oitocentos, o intendente dos diamantes Manoel Ferreira da Câmara Bittencourt e Sá mandou construir, do Tijuco para o vizinho povoado de Mendanha, uma estrada monumental calçada de grandes lajes, à semelhança das antigas vias romanas (A Idea Nova, ano V, n.206, 20.03.1910, p.1. Biblioteca Antônio Torres). Tal obra empregava materiais abundantes na região: as rochas e a areia fina como material de agregação. A segunda iniciativa remonta ao ano de 1858, quando, por contrato com o governo da Província, Ezequiel Neto Carneiro começou a construção da ponte de Mendanha, exclusivamente para o trânsito de tropas e pedestres, pagando-se vinte réis por pedestre e 
quarenta réis por animal. Essa ponte, cuja extensão alcançava $107 \mathrm{~m}$, era fechada no centro, onde se via uma coberta, debaixo da qual as moças do arraial faziam serenatas às noites de luar. A inauguração da ponte de Mendanha ocorreu em 1863 (Voz de Diamantina, 01.02.1948).

Os trechos de estrada construídos pelo intendente Câmara e a ponte de Mendanha revelam os problemas técnicos associados às estradas para transporte a tração animal, existentes na região de Diamantina. As fortes rampas precisavam de revestimento para diminuir o esforço de tração dos animais. ${ }^{14}$ O empedramento ordinário exige maior esforço do que o leito de terra socado, que é mais exigente do que o revestimento de cascalho; este último, por sua vez, força mais os cargueiros do que o macadamo ou revestimento de paralelepípedos bem talhados (cf. Corrêa \& Bacelar, op. cit.). Para calçar com lajes os trechos íngremes da estrada de Diamantina para Mendanha, as turmas de trabalhadores escravos sob o comando do Intendente realizaram diversas operações: para regularização do leito da estrada, derrubaram o mato, empurraram e transportaram terra, nivelaram e compactaram o solo; para o revestimento do leito, abriram caixas preenchidas com gorgulho e areia grossa, sobre as quais assentaram pedras, socadas uma a uma e rejuntadas por pó de pedra e areia fina, sob constante umidificação; e, para escoar as enxurradas, construíram valetas e bueiros. Em alguns trechos da estrada, também construíram banquetas, espécies de meios-fios de pedra que eram proteções contra acidentes.

Tudo isto com o emprego de ferramentas simples: pás, enxadas, alviões ou enxadões, picaretas, alavancas, bimbarras. Para remover blocos de pedra, utilizaram cunhas e pólvora. Se fosse preciso vencer uma pequena pedreira, cujo contorno fosse muito difícil ou impossível, recorria-se à escavação a fogo - abria-se na rocha um furo profundo com marreta e ferramenta de aço, dentro do qual se colocava fogo, provocando assim a fragmentação da pedreira.

As pontes sobre os córregos e rios, por seu turno, eram construídas com grandes esteios e vigas de madeira de lei, produzidos a partir dos paus abundantes nas matas da região. $\mathrm{O}$ assoalho das pontes costumava ser feito de madeira menos nobre. ${ }^{15}$ A ponte de Mendanha era toda de madeira e não possuía guarnições de pedra. Já a ponte sobre o córrego Junta-Junta, com extensão de 14 metros, inaugurada em 31 de março de 1910 — obra do Major João Avelino Pereira, sob a direção do engenheiro Domingos Fleury da Rocha era construída em madeira de lei, pintada a piche e guarnecida por pedreiras de alvenaria com mais de cinco metros de altura (A Idea Nova, ano V, n.209, 10.04.1910. Biblioteca Antônio Torres). 
O padrão técnico que as autoridades mineiras desejavam imprimir às estradas da região de Diamantina, na virada do século XIX para o XX, é delineado em relatório datado de 2 de março de 1876, escrito pelo engenheiro interino do $5^{\circ}$ Distrito, Albert Schirmer, contendo o orçamento das pontes e dos consertos da Estrada do Gavião. Segundo o engenheiro:

Na execução da obra serão condições gerais as seguintes: a) o leito da estrada nunca terá menos de 2,50 m; b) a derrubada como a vassada será de $20 \mathrm{~m}$ de largura a cada lado da estrada; c) as sarjetas não terão menos de trinta metros uma da outra; d) as avenidas das pontes e dos pontilhões serão construídas com todo esmero possível, pondo-se sempre uma camada de gorgulho de $33 \mathrm{~cm}$ de espessura e $5 \mathrm{~m}$ de largura; devem ser boleadas e bastante elevadas a fim que as águas ali não possam estagnar-se. $\left(\mathrm{OP}_{6}^{3}, \mathrm{Cx} .8\right.$, Doc. 06. Arquivo Público Mineiro)

Todavia, o desejo das autoridades em relação às estradas não era de fácil concretização. A falta de recursos, as características do relevo e da meteorologia regionais conspiraram contra a qualidade dos caminhos que levavam a Diamantina. Situação exposta limpidamente no Memorial sobre a estrada do Serro, escrito em 28 de fevereiro de 1917 pelo engenheiro B. Jardim:

A estrada de Diamantina a Serro foi construída nos tempos coloniais, quando o antigo Tijuco se achava dependente da Vila do Príncipe e o seu traçado com poucas modificações é até hoje o mesmo, defeituosíssimo, se não podendo ser modificado sem grandes dispêndios devido à topografia da zona e a constituição do solo. Durante o Império teve ela sempre um encarregado da sua conserva pago pelo governo, sendo o mesmo dispensado em 1889, o que a prejudicou muito, pois que em 1891 já o seu leito estava estragadíssimo, reclamando sérios reparos, que foram finalmente executados de 1896 para 1897, ficando porém de então para cá sem a necessária conserva, cuja conseqüência foi se tornar intransitável, por mais de dois anos. Em fevereiro de 1916 apresentei um orçamento para os reparos indispensáveis, não tendo sido executados... (Relatório sobre a realização de obras públicas. Secretaria da Agricultura - AS. Série AS, anexo. n.917. Arquivo Público Mineiro)

O resultado previsível do estado de contínua precariedade das estradas no Alto Jequitinhonha era duplo: o encarecimento dos transportes e a lentidão das viagens. Conforme o engenheiro B. Jardim, no ano de 1917, gastavam-se do Serro a Diamantina, ida e volta, de 6 a 8 dias de viagem. 


\section{O FLUXO DOS CARGUEIROS E AS VARIÁVEIS AMBIENTAIS}

A influência das variáveis ambientais sobre os padrões de transporte de bens e pessoas na região do Alto Jequitinhonha foi bastante acentuada, indo além da oferta ampla de cascalho, lajes de pedra e madeiras de lei para emprego na construção de estradas e equipamentos de transporte. Na realidade, essa influência explica a longa permanência do "antigo sistema de circulação" na referida zona.

O primeiro fator decisivo é a topografia extremamente acidentada da região. Para o tipo de relevo do Alto Jequitinhonha, os animais de sela acomodavam-se relativamente bem, mesmo nas inclinações pronunciadas. ${ }^{16}$ Era suficiente abrir para os cargueiros picadas entre a vegetação, ou talhar degraus nas vertentes muito íngremes. A topografia, porém, tornava praticamente impossível o emprego dos carros e das carroças nos caminhos ao redor de Diamantina. Isto porque, conforme Paul Claval, “a roda só é utilizável nas vias que apresentam superfícies duras e planas e vencem as rupturas através de pontes" ${ }^{17}$ Carros e carroças requerem, portanto, o concurso de técnicas de organização do espaço - abertura de cortes ou de túneis, construção de aterros, elaboração e compactação do piso - o que implicava, para a região em tela, consideráveis movimentos de terra e muitas dificuldades para remover grandes quantidades de rochas. Assim, as estradas do Alto Jequitinhonha foram domínio exclusivo das caravanas de muares, até a década de 1930. Nem mesmo o tradicional carro de boi, bastante empregado em outras partes do Brasil, se fez presente no transporte de cargas e pessoas no entorno de Diamantina.

O relevo movimentado também contribuiu para limitar a eficiência dos animais cargueiros, que se cansavam mais rapidamente nas rampas dos caminhos. Nas subidas e descidas das serras, especialmente quando o leito das estradas se encontrava escavado pelas enxurradas, o trânsito tornava-se perigoso por causa das sinuosidades e dos abismos. A ponto de H. D. Beaumont afirmar, em 1899, que a "descida da serra do Mendanha estava horrível com as muitas escavações das águas pluviais, vendo-se a cada momento o perigo diante dos olhos" (O Município, ano IV, n.228, 02.06.1900, p.2. Biblioteca Antônio Torres). Anos depois, em 1906, um jornal diamantinense anunciou que, na estrada de Mendanha, "três animais [haviam sido] mortos quando tentavam atravessa-la ... prova sinistra e incontestada do perigo constante oferecido às tropas em trânsito para o nosso mercado (A Idea Nova, ano I, n.2, 29.04.1906, p.2. Biblioteca Antônio Torres). 
As características do solo nas áreas de campos rupestres, de pequena porosidade, criavam outra dificuldade para as tropas e viajantes. Freqüentemente, os animais eram retardados por causa dos brejos, que se transformavam em lagoas intransponíveis no tempo das chuvas. Nos muitos meses chuvosos do ano, quando era comum as águas caírem desde a manhã até escurecer sem sequer um pequeno intervalo, os trechos dos caminhos nessas áreas enchiamse de lama. Durante a marcha, o barro cobria até o alto da cabeça dos homens e animais. É o que revela o depoimento de Nestor Araújo: "nas estradas tinha lugar em que os tropeiros tiravam os couros de boi que cobriam as cargas e botavam no chão para a tropa poder passar em cima e o animal não afundar". O acúmulo da água nos terrenos mais planos gerava atoleiros de difícil ultrapassagem, nos quais os animais corriam riscos maiores de acidente, além de perderem capacidade de tração e se fadigarem inutilmente.

Nos trechos de serra, as chuvas derrocavam os caminhos. As fortes enxurradas danificavam as obras de calçamento das estradas, esburacavam longos trechos, faziam surgir repentinamente fossos profundos onde antes havia o leito do caminho. As subidas e descidas tornavam-se, portanto, mais penosas e perigosas. Na estrada de Mendanha, nas muitas ocasiões em que ela se encontrava estragada, havia trechos nos quais o viajante era obrigado a apear do cavalo na serra (A Idea Nova, ano V, n.206, 20.03.1910, p.1. Biblioteca Antônio Torres).

O principal problema causado pelas chuvas era a interrupção, muitas vezes por várias semanas, das passagens pelos rios e córregos, especialmente no Jequitinhonha, no Araçuaí, no rio Preto, no rio do Peixe, no Junta-Junta. A maioria dos cursos d'água da região corre em leito de pedra, encaixotada em calha estreita. Dessa forma, transbordam repentinamente, levando as pequenas pontes de madeira e os viajantes apanhados de surpresa.

A documentação sobre as estradas da região de Diamantina, existente no Arquivo Público Mineiro e na Biblioteca Antônio Torres, permite elaborar o Quadro 2, com ocorrências de quedas de pontes. 
Quadro 2

Pontes destruídas por enchentes - Diamantina - 1872 a 1907

\begin{tabular}{lcc}
\hline Ano & Ponte caída & Localidade \\
\hline 1872 & Rio Jequitinhonha & São Gonçalo \\
\hline 1876 & Córrego Junta-Junta & Curralinho \\
\hline 1882 & Rio do PeixeTrês & Barras \\
\hline 1886 & Rio Preto & $\begin{array}{c}\text { São Gonçalo } \\
\text { do Rio Preto }\end{array}$ \\
\hline 1906 & Ribeirão do Inferno & - \\
\hline 1907 & Córrego da Fome & Rio Manso \\
\hline
\end{tabular}

Fonte: Documentos diversos. APM e BAT.

O mais comum era que essas pontes destruídas pelas enchentes ficassem longo tempo à espera da reconstrução. Em 1886, o jornal Sete de Setembro trouxe a seguinte notícia:

Ponte do Rio Preto. A enchente do rio deste nome levou o resto da velha ponte. Sua falta vai interromper o trânsito e o comércio entre este município e os que ficam ao norte. O correio de Minas Novas, que devia ter chegado a esta cidade no dia 14, ficou além de suas margens, de braços cruzados a olhar as malas, a esperar que baixassem as águas para continuar a sua viagem. (Sete de Setembro, ano I, n.15, 30.11.1886, p.2. Biblioteca Antônio Torres)

A mesma ponte ainda não havia sido inteiramente reconstruída em 1910, a julgar pela matéria publicada num jornal diamantinense:

Ponte do Rio Preto. O nosso amigo Carlos Souto ... referiu-nos que, encontrando-se com o Coronel Ignácio Murta, pediu ao ilustre político obter do governo de Minas a terminação da ponte do Rio Preto, que importaria ao máximo em $800 \$ 000$ rs, fazendo-lhe ver o grande prejuízo que pode haver naquela obra, com a entrada das chuvas. (A Idea Nova, ano V, n.224, 24.07.1910, p.1. Biblioteca Antônio Torres)

A ponte sobre o Ribeirão do Inferno, destruída em 1906 (A Idea Nova, ano I, n.17, 05.08.1906, p.1. Biblioteca Antônio Torres), permanecia "em estado de 
completa ruína, a ponto de impedir o trânsito" no final do ano de 1920 (Pão de Santo Antônio, ano XIV, n.10, 14.11.1920, p.1. Biblioteca Antônio Torres).

O fenômeno recorrente das fortes enchentes talvez explique por que, até a década de 1920, não foi construída a ponte sobre o rio Araçuaí, na Estrada Geral do Norte, nas proximidades do povoado de Mercês. Em 1899, H. D. Beaumont relatou que, para ir do arraial de Rio Preto para o de Mercês, teve "que atravessar o rio Araçuaí por uma pinguela, um pau lavrado em uma das faces e estirado ao largo do rio, e os animais passaram a nado" (O Município, ano IV, n.228, 02.06.1900, p.2. Biblioteca Antônio Torres). Pinguelas podem ser facilmente improvisadas se uma enchente levar a anterior rio abaixo. Já as pontes não, porque são de construção difícil, demorada e cara.

É claro que as dificuldades para a travessia de rios e córregos diminuíam bastante no período da seca, especialmente entre os meses de abril e agosto. Porém, não desapareciam completamente. Os cursos d'água do Alto Jequitinhonha são traiçoeiros, porque correm em caixas estreitas sulcadas no meio de rochas. Basta uma chuva isolada e imprevista na cabeceira do rio para que uma torrente poderosa percorra o curso a vazante, arrastando homens e animais desprevenidos. As memórias dos tropeiros do município de Diamantina contêm relatos de acontecimentos trágicos desse tipo. Além disso, muitos locais de travessia de tropas sobre os cursos d'água escondiam armadilhas, os fossos mais profundos entre bancos de areia e grandes rochas submersas logo abaixo da linha d'água. O senhor Augusto Domingos Ribeiro narrou perdas de animais e cargas ocorridas por causa desses fossos nos rios. Conforme suas palavras,

[no primeiro ribeirão logo após São Gonçalo] eu ia passando com minha tropa, e vinha outro tropeiro carregado com dois sacos de arroz. Tinha um passadinho ruim na estrada, lá dentro do rio ... Veio o tropeiro e a tropa, entraram no rio e passaram. E vinha uma mula carregada, pesada mesmo, e tinha um poção embaixo, a mula pegou e afundou. Só víamos a mula soprando, o ar voltando para cima da água. E quem disse que ela agüentou? Corre daqui, corre dali, mas com oito, dez arrobas... Dá para afundar. A mula acabou morrendo.

Este episódio, que ocorreu por volta de 1952, demonstra que prejuízos rondavam os tropeiros diante de qualquer descuido. Quem lidava com os cargueiros durante as viagens estava sujeito à perda das cargas e dos animais. $\mathrm{O}$ único seguro de que dispunham os tropeiros era seu próprio saber profissional, sua experiência acumulada no vai-e-vem pelas trilhas. Isso explica por 
que o sucesso do tropeiro dependia de sua capacidade de observação das variáveis e dos fenômenos ambientais, tanto quanto da memorização dos caminhos que percorria.

A cada ano, a chegada do inverno no Alto Jequitinhonha também trazia dificuldades para a circulação das tropas. Mais desconforto para os animais e viajantes do que propriamente perigos como os representados pelas chuvas e enchentes. Em primeiro lugar, os dias ficavam mais curtos e as noites mais escuras e frias. Por isso, o tempo útil para a marcha das tropas reduzia-se. Em segundo lugar, desde o cair da tarde até as primeiras horas da manhã, nas partes altas das serras, as trilhas cobriam-se de espessa névoa e tornavam-se geladas. O pouso da tropa transformava-se numa penosa espera dos raios do sol. Sobre isto, vale lembrar o que escreveu o Secretário da Legação Britânica no Rio de Janeiro, H. D. Beaumont, quando viajava nas imediações do Capivari, localidade próxima ao Pico do Itambé:

A noite estava clara, a lua brilhava, fazia frio. Para nos estorvar o menos possível, tínhamos levado um único cobertor. Entretanto, graças aos nossos capotes que não largamos não sentimos muito frio. José e seus companheiros [os tropeiros da comitiva] não tinham coberta alguma e, segundo o hábito do Brasil, viajavam descalços. Não podemos compreender como eles tinham conseguido passar a noite assim vestidos. Eles tinham estado acordados junto ao fogo, porém sem dormir um instante. (O Município, ano IV, n.230, 16.06.1900. Biblioteca Antônio Torres)

Em anos excepcionalmente frios na região, chegavam a acontecer mortes de mulas nos pousos situados em pontos altos das trilhas, conforme aponta a memória dos moradores de Diamantina. ${ }^{18}$

O fluxo das tropas, portanto, era dificultado, no curso de cada ano, pela combinação variável, conforme a estação, das temperaturas, da pluviosidade e da vazão dos rios. Sobre esse fluxo também incidiam, prejudicando-o, as condições topográficas do entorno de Diamantina, dominado por serras elevadas, encostas escarpadas, vales estreitos onde os afloramentos de pedra estão pulverizados por toda a superfície dos terrenos. Conseqüentemente, os custos de transporte para o principal mercado do Nordeste mineiro tornavam-se mais elevados, refletindo sobre os preços das mercadorias à venda no comércio da cidade. Muitas áreas rurais, como é o caso da Mata de Peçanha, tiveram seu crescimento agrícola contido pela falta de vias de transporte para o escoamento rápido e seguro da produção das roças. O serviço postal torna- 
va-se irregular e os custos dos fretes elevados, enquanto o funcionamento das empresas comerciais e industriais da região ficava bastante dificultado. Conforme a Câmara Municipal de Diamantina, a queda da ponte de São Gonçalo sobre o rio Jequitinhonha, ocorrida em 13 de novembro de 1872, teria provocado, em três dias, a elevação dos preços dos mantimentos ao triplo dos praticados quando a estrada dava passagem normal para as tropas (Ofício da Câmara Municipal de Diamantina ao Presidente da Província, de 23.11.1872. Secção provincial, códice Obras Públicas, caixa 37, documento 27. Arquivo Público Mineiro). Situações semelhantes de alta de preços de mantimentos ocorreram praticamente ano após ano no mercado de Diamantina, no período entre 1870 e 1930. A simples aproximação da estação chuvosa disparava o movimento de especulação entre as maiores casas comerciais da cidade.

A precariedade das estradas regionais, cuja manutenção era praticamente inviabilizada pelas variáveis ambientais mencionadas anteriormente, também ameaçava a implantação de investimentos nacionais e estrangeiros no Alto Jequitinhonha, particularmente os que se destinavam ao setor mineral. É o que se pode inferir a partir, por exemplo, das considerações feitas pelo Dr. Catão Gomes Jardim, em ofício de 11 de dezembro de 1882:

a companhia ultimamente organizada em Paris para exploração de diamantes neste município, pelo seu engenheiro o Dr. Du Boivel, fez-me sentir que não poderá dar princípios aos trabalhos preliminares, sem que sejam reparados alguns pontos da estrada entre Diamantina e o Serro, e que ficaram assim adiados os referidos trabalhos com graves prejuízos da predita companhia ... Deve-se mais atender que as dificuldades criadas às companhias pela falta de viação pública irão produzir mau efeito nas praças européias, arredando novos capitais que se destinam a empresas nas províncias centrais... (Secção Provincial, códice Obras Públicas, caixa 08, documento 05. Arquivo Público Mineiro)

De uma outra maneira decisiva os fatores ambientais influenciaram a trajetória do sistema viário e dos transportes no Alto Jequitinhonha, obstruindo sua modernização. Além do desafio portentoso que as paisagens naturais da região colocavam e ainda hoje colocam para a construção e a manutenção de boas estradas de rodagem, devem ser levadas em conta as interações entre o quadro de recursos naturais úteis e as disposições e atitudes dos agentes econômicos nos diferentes momentos históricos do Nordeste mineiro. O papel central do diamante e do ouro na formação regional pesou também sobre os 
processos relacionados à circulação de pessoas e mercadorias. Vale fazer algumas observações sobre isto.

Entre as décadas de 1890 e 1910, os municípios de Diamantina e Serro lutaram um contra o outro pela construção de ramal ferroviário ligando a região ao Sul do país. A aproximação dos trilhos da Estrada de Ferro Central do Brasil despertou os jornais diamantinenses para a oportunidade da construção de vias para o tráfego de carruagens articuladas com a ferrovia. Segundo um dos mais importantes periódicos locais,

agora que se ataca fortemente o serviço da linha férrea Vitória a Diamantina, de modo a podermos ver, no breve espaço de cinco anos o carro do progresso às portas da cidade, impõe-se como necessidade urgente, inadiável, o melhoramento das estradas de rodagem que a ligam aos diversos pontos do Estado, ainda não servidos por estradas de ferro. (O Jequitinhonha, 04.08.1904. Biblioteca Antônio Torres)

A oportunidade vislumbrada pelos homens de imprensa parece ter sido percebida também por alguns homens de negócio de Diamantina. Em 1902, alguns deles, dentre os quais se destacavam Luiz de Rezende, Antônio Botelho Guerra, Antônio Eulálio de Souza, Anselmo Pereira de Andrade e João Felício dos Santos, solicitaram ao Congresso Mineiro privilégio e garantia de juros do capital de dois mil contos de réis, para a construção de uma estrada de rodagem pelo sistema Caillet's Monorail por tração animal ou vapor, que ligaria Diamantina ao ponto terminal da Central do Brasil. Pediram uso e gozo por cinqüenta anos. O projeto tornou-se lei em 15 de setembro de 1902, mas o empreendimento não se concretizou. Em 1907, a Empresa de Transportes Norte de Minas, pertencente a Almeida \& Cia., iniciou a operação de uma linha de carruagens de tração animal na estrada Diamantina a Curralinho (atual Corinto). Do Largo Dom João, em Diamantina, até a Estação de Curralinho a viagem durava dois dias. Cada carruagem levava quatro pessoas, ao preço de 500 mil réis por passageiro. O funcionamento da empresa foi curto, cerca de três anos. ${ }^{19}$

Outra estrada de rodagem foi construída por William G. Mayer, ligando Diamantina ao município de Curvelo. A disposição do empresário americano, diretor de uma empresa estrangeira de mineração, foi noticiada pelo jornal O Jequitinhonha, em julho de 1905:

De há muito pesa a necessidade de se facilitar o trajeto desta cidade a uma das mais próximas estações da E. F. Central do Brasil ... Neste sentido foi que o sr. 
W. G. Mayer fundou esta companhia, propondo-se a criar uma estrada de rodagem que partindo desta cidade, vá à estação de Cachopa, no município de Curvelo, com um percurso de 21 léguas, ligando-a assim aos grandes centros comerciais e manufatores, com mais brevidade, fácil transportação e perfeita segurança. (O Jequitinhonha, 21.07.1905. Biblioteca Antônio Torres)

A “estrada do Mayer” passava pelos arraiais de Riacho das Varas (atual Conselheiro Matta), Nossa Senhora da Glória e Papagaio, possuindo estações intermediárias entre Diamantina e Cachopa; os viajantes e as cargas cruzavam o rio das Velhas por barca, por conta da companhia de Mayer. As obras de construção dessa estrada obtiveram ajuda do governo estadual, no valor de quinze contos de réis (O Jequitinhonha, 03.08.1905. Biblioteca Antônio Torres). A estrada alcançou Mendanha, distrito situado ao norte de Diamantina, em 1906. Para percorrê-la integralmente, os trolleys da Companhia de Transporte Norte de Minas gastavam três dias. Contudo, a rodovia construída pelo empresário americano logo começou a apresentar problemas. No início de 1906, os moradores do arraial de Nossa Senhora da Glória queixaramse das dificuldades impostas pelo leito esburacado e erodido da referida via, escrevendo:

Vias sacras do comércio, cheias de atoleiros onde os carros se atolam, quebrando a cabeça aos passageiros, triturando os braços e pernas e deixando as mulheres com os seus filhos à cacunda no meio da estrada, à mercê do tempo, tudo isso sabe o Governo Municipal, é prova superabundante que a estrada do caprichoso Mayer não está construída em lugares sólidos e não deve o dito governo apoiá-la com os cofres do erário que também temos lá, neles, nossa parcela. (O Jequitinhonha, 03.03.1906. Biblioteca Antônio Torres)

A Companhia de Mayer funcionou com problemas crescentes por poucos anos. A estrada caiu em desuso no início da década de 1910, e esse fato marcou o fim do sonho dos homens de imprensa que queriam ver toda a região cortada por modernas rodovias, interligando cidades, povoados, áreas agrícolas e de mineração com as estações ferroviárias mais próximas.

O fracasso de Almeida \& Cia. e, principalmente, da Companhia de Transportes Norte de Minas encerrou definitivamente os tímidos investimentos dos homens de negócio de Diamantina em estradas de rodagem e empresas de transporte. A maioria deles, apegados ao garimpo de diamante e ouro, con- 
venceu-se, em primeiro lugar, de que tais insucessos demonstravam o risco e a pequena lucratividade que advinham do negócio de construir estradas e explorá-las por meio de empresas de transporte por carros e carruagens. Em segundo lugar, para os mais conservadores, as vultosas inversões necessárias para abrir e manter boas rodovias eram vistas como um inaceitável desvio de capitais da mineração, atividade a que já estavam longamente habituados, e que lhes parecia ser a "vocação econômica regional". Em terceiro lugar, na virada do século XIX para o século XX, durante o efêmero funcionamento das companhias de transporte rodoviário, os homens de fortuna de Diamantina tiveram oportunidade de perceber que as rodovias provocaram impacto bastante marginal sobre a dinâmica das lavras, tanto no que se refere aos custos de operação dos garimpos quanto no que se refere à velocidade de comercialização dos minérios extraídos. Dos serviços de mineração até a praça de Diamantina, as pedras preciosas e o ouro podiam ser transportados facilmente por homens a pé ou a cavalo. Esse transporte nunca constituíra um problema para os mineradores, uma vez que os produtos das lavras exploradas no Alto Jequitinhonha possuíam altíssimo valor por unidade de peso. Se havia uma dificuldade de transporte que preocupava os mineradores e os "diamantários” (nome regional dado aos negociantes de pedras), ela estava relacionada com a necessidade de levar até a praça de exportação — o mercado do Rio de Janeiro - , no menor tempo possível, os diamantes extraídos no entorno de Diamantina. Mas essa dificuldade foi resolvida perfeitamente com a chegada da estrada de ferro ao antigo arraial do Tijuco, no ano de 1914.

Essa situação contrastava vivamente com a da Zona da Mata e do Sul de Minas. Nestas duas regiões, a riqueza principal, o café, teve sua rentabilidade e sua expansão associadas, entre outros fatores, à redução dos custos de transporte até os portos de exportação, o que levou os fazendeiros a formar companhias de transporte ferroviário e a investir também em estradas de rodagem, como a União e Indústria. ${ }^{20}$ No Alto Jequitinhonha, os mineradores e os "diamantários", detentores das maiores fortunas regionais, não compartilharam com os fazendeiros e os industriais o desejo de modernizar o transporte entre os núcleos urbanos, as áreas agrícolas e as lavras da região. ${ }^{21}$ Para os homens ligados à mineração, o "antigo sistema de circulação", baseado nas tropas de muares, ajustava-se bem às necessidades da atividade garimpeira, o setor dinâmico da economia regional desde o século XVIII.

Essa visão míope dos grandes mineradores e negociantes de diamante sobre o problema do transporte no Alto Jequitinhonha gerou conseqüências 
negativas para a economia regional. Isto porque o investimento em empresas de transportes rodoviários poderia ter estimulado a acumulação interna de capitais e de capacidades de engenharia, gestão e empreendedorismo, promovido a difusão do emprego de trabalhadores qualificados nas oficinas e estações de coches, além de proporcionar oportunidades de treinamento de diferentes grupos de empresários, acostumando-os à separação entre propriedade e gerência (uma das principais características da moderna empresa). ${ }^{22} \mathrm{~A}$ combinação de ferrovia e rodovias pavimentadas no entorno de Diamantina teria quebrado a inércia e o baixo dinamismo econômico associados ao "antigo sistema de circulação".

Ao fim e ao cabo, a consideração cautelosa dos fatores ambientais ajuda a entender por que, no âmbito do transporte de pessoas e mercadorias, a região de Diamantina desligou-se tão lentamente das estruturas do passado. Apenas na década de 1960 as tropas de muares perderam a condição de principal meio de ligação entre a cidade, os distritos, os povoados e os diversos municípios do Vale do Jequitinhonha sob a influência comercial, político-administrativa e educacional de Diamantina.

\section{NOTAS}

${ }^{1}$ Ver NEVES, José Augusto. Corografia do Município de Diamantina. In: NEVES, Jayme. José Augusto Neves: o jornalista-escritor, sua obstinação e vocação ecológica. Belo Horizonte: Imprensa Oficial, 1986.

${ }^{2}$ ABREU, Capistrano de. Os caminhos antigos e o povoamento do Brasil. 5.ed. Brasília: Ed. UnB, 1963.

${ }^{3}$ As informações sobre a composição das tropas da região de Diamantina são retiradas dos depoimentos dos ex-tropeiros José Maria Lopes, Augusto Domingos Ribeiro, Nestor Araújo e Joaquim dos Santos Júnior, recolhidos pela equipe do Projeto "Paragens da Memória", financiado pela Fapemig em 2004.

${ }^{4}$ Depoimento de Joaquim dos Santos Júnior. São Gonçalo do Rio das Pedras, Minas Gerais, julho de 2004. 1 fita cassete (60 min). Entrevista concedida a Tatiana Gonçalves da Silva e Andréa Casa Nova Maia.

${ }^{5}$ Depoimento de Augusto Domingos Ribeiro. São Gonçalo do Rio das Pedras, Minas Gerais, julho de 2004. 1 fita cassete $(60 \mathrm{~min})$. Entrevista concedida a Tatiana Gonçalves da Silva e Andréa Casa Nova Maia.

${ }^{6}$ Cf. depoimento de Augusto Domingos Ribeiro. Cf. também o depoimento de Nestor 
Araújo. São Gonçalo do Rio das Pedras, Minas Gerais, julho de 2004. 1 fita cassete (60 min). Entrevista concedida a Tatiana Gonçalves da Silva e Andréa Casa Nova Maia.

${ }^{7}$ Depoimento de José Maria Lopes. Córrego do Mel, Minas Gerais, setembro de 2004. 1 fita cassete (60 min). Entrevista concedida a Tatiana Gonçalves da Silva e Rogério Pereira Arruda.

${ }^{8}$ Ver CALÓGERAS, Pandiá. Transportes arcaicos. In: Estudos históricos e políticos. São Paulo: Cia. Ed. Nacional, 1927. (Col. Brasiliense, Pequeno Formato, v.75.)

${ }^{9}$ Cf. ARNO, Ciro. Memórias de um estudante. 2.ed. Rio de Janeiro: Gráfica Olímpica, 1949. p.116.

${ }^{10}$ Ver ANASTASIA, Carla Maria Junho. Salteadores, bandoleiros e desbravadores nas Matas Gerais da Mantiqueira. In: PRIORE, Mary Del (Org.) Revisão do paraíso: os brasileiros e o Estado em 500 anos de história. Rio de Janeiro: Campus, 2000. p.115-38.

${ }^{11}$ Cf. Fala que Exm. Sr. Dr. Antônio Gonçalves Chaves dirigiu à Assembléia Legislativa Provincial de Minas Gerais na $1^{\text {a }}$ sessão da 25a legislatura, em $1^{\circ}$ de agosto de 1884. Ouro Preto: Typ. do Liberal Mineiro, 1884. Arquivo Público Mineiro.

${ }^{12}$ Cf. depoimento de José Maria Lopes, já citado.

${ }^{13}$ Para mais detalhes, consultar CORRÊA, Ernani D.; BACELLAR, Rui H. (Org.) Manual do engenheiro. Porto Alegre: Globo, 1939. v.II, p.A94-A121.

${ }^{14} \mathrm{O}$ cavalo (ou o burro) tem seu esforço de tração proporcional ao peso e limitado pelo escorregamento das patas sobre a superfície da estrada.

${ }^{15}$ Por isso, o piso das pontes durava pouco tempo, castigado pelo trânsito dos animais carregados e pela ação das chuvas. Necessitavam reparos permanentes, como se depreende da matéria seguinte, publicada em jornal de Diamantina: "Ponte do Mendanha. Voltamos mais uma vez a chamar a atenção dos poderes públicos para o estado deplorável em que acha a ponte do Mendanha, cujo assoalho está todo apodrecido e crivado de grandes buracos. As tropas e os viandantes já recorrem ao vau, expondo a própria vida" (Pão de Santo Antônio, ano X, n.51, 1917, p.1. Biblioteca Antônio Torres).

${ }^{16}$ Conforme o relatório do engenheiro B. Jardim, de 1917, a estrada do Serro a Diamantina possuía diversos trechos com inclinações iguais ou superiores a 50 por cento, nas serras do Ribeirão, da Bocaina e do Pinheiro.

${ }^{17}$ CLAVAL, Paul. A geografia cultural. Florianópolis: Ed. UFSC, 1999. p.250.

${ }^{18}$ Depoimento de Daniel Luiz Nascimento. Diamantina, Minas Gerais, julho de 2004. 1 fita cassete (60 min). Entrevista concedida a Tatiana Gonçalves da Silva e Rogério Pereira de Arruda.

${ }^{19}$ As informações sobre a Empresa Almeida \& Cia. e o projeto de estrada operada pelo sistema Caillet's Monorail estão em COUTO, Soter Ramos. Vultos e fatos de Diamantina. 2.ed. Belo Horizonte: Armazém de Idéias, 2002. p.226-8. 
${ }^{20}$ Ver o trabalho de Peter BLASENHEIM. Railroads in Nineteenth-Century Minas Gerais. Journal of Latin American Studies, v.26, p.356ss. Para o caso paulista, ver SAES, Flávio A. M. de. As ferrovias de São Paulo 1870-1940. São Paulo: Hucitec, 1981.

${ }^{21}$ Para análise detalhada sobre as escolhas econômicas e os projetos de desenvolvimento regional formulados pelos homens de negócio de Diamantina no período considerado, ver MARTINS, Marcos Lobato. Os negócios do diamante e os homens de fortuna na praça de Diamantina, MG: 1870-1930. São Paulo, 2004. 304p. Tese (Doutorado em História Econômica) — Faculdade de Filosofia, Letras e Ciências Humanas, USP.

${ }^{22}$ Sobre as relações entre redes de transporte e desenvolvimento regional, ver GIROLETTI, Domingos. A modern transport network and the industrial development of Brazilian Southeast, 1850 to 1890. In: Anais da $2^{a}$ Conferência Anglo-Brasileira de Negócios. Belo Horizonte, p.39-54, mar. 1999. 